still pervades Britain, although it takes just as much brains to become a first-class technologist as to become a first-class lawyer, and probably more. Since this battle which he has fought for the past twenty years has been unsuccessful, Lord Cherwell found the reason for his being awarded the Messel Memorial Medal in his early work on physical chemistry, dating from that with Prof. W. Nernst in Berlin more than forty years ago. Nernst was then mainly concerned with the heat theorem known as the third law of thermodynamics, and Lord Cherwell showed briefly how a suggestion by Einstein regarding the derivation of Planck's formula led to the discovery that action could only be transferred in units of a minute but finite size. The processes for synthesizing ammonia or petroleum depend, in fact, on the reinstatement in a space-time description of the conjugated dynamical co-ordinate.

The world is now entering an epoch of nuclear chemistry, continued Lord Cherwell, about which our knowledge is as rudimentary as that of chemistry itself a hundred and fifty years ago. No one can say whether the building up or the breaking down of nuclei will play the predominant part in generations to come. Even in classical chemistry there are problems of which we have only scratched the surface, such as the extraction of the uranium and the plutonium after irradiation from the rods full of lethal fission products and the disposal of these intensely active products. Whether we can utilize the energy potentially available has yet to be seen, and meanwhile man for the first time has it in his power to destroy all life on this planet. The question is whether he will be able to avoid some such form of universal suicide, and it is a sad reflexion on our political achievements and mental processes that, despite the universal wish for peace, man has not been able so to arrange his affairs as to avoid war and the continuing threat of war.

\section{STANDARDS AND LEVELS OF LIVING}

A COMMITTEE of United Nations experts has A concluded that most of the short-cut methods for comparing levels of living in different countries are unsuitable and sometimes misleading. For example, both national income per capita and real wages have serious defects as indexes of levels of living*.

To present useful comparison the committee recommends a pluralistic approach by analysis of various 'components' of living which are amenable to quantitative treatment and reflect internationally accepted values or aims. 'The twelve components listed by the experts are: health, including demographic conditions ; food and nutrition; education, including literacy and skills; conditions of work; employment situation; aggregate consumption and savings; transportation; housing, including household facilities; clothing; recreation and entertainment; social security; and human freedoms.

In addition, the report includes a series of more specific statistical indicators that should be used as

* Report on International Definition and Measurement of Standard and Levels of Living. (Report of a Committee of Experts convened by the Secretary-General of the United Nations, jointly with the International Labour Office and Unesco.) Pp. xii +96. (New York : United Nations; Jondon: H.M. Stationery Office. 1954.) 0.80 dollars; $6 s$. 3 Swiss francs. a guide in measuring the various components; these indicators are chosen with the view of availability of information. In view of deficiencies of data in many countries, however, the report gives a minimum list of 'priority indicators'; it indicates how they may be obtained and adds another set of indicators to illustrate lines of further improvement.

Members of the committee recognized that an international analysis of levels of living, in terms of the components and indicators they proposed, would nevertheless fall short of giving a complete and balanced picture of the total situation. They stressed the importance of the use of descriptive materials and background information, particularly in the form of social and cultural analyses. A more direct and comprehensive assessment may be attainable by 'family living surveys' carried out by the use of sampling methods and designed to ensure international comparability.

The committee was appointed by the Secretary. General of the United Nations, jointly with the International Labour Organization and the United Nations Educational, Scientific and Cultural Organization. Members came from six different countries and represented various disciplines of social sciences and statistics. They were Prof. Raymond Firth, professor of anthropology in the London School of Economics and Political Science; Prof. Philip M. Hauser, professor of sociology in the University of Chicago; Mr. Erland v. Hofsten, chief of the Statistical Section, Social Welfare Board of Sweden ; Father Louis Joseph Lebret, editor of Economie et Humanisme, France; Mr. O. Alexander Moraes, acting secretary-general of the Inter-American Statistical Institute of the Organization of American States; and Mr. V. K. R. V. Rao, director of the Delhi School of Economics, University of Delhi.

\section{MANAGEMENT COSTS}

THE costs of managing industrial firms have traditionally been regarded as an incidental class of expenditure. These costs have been rising rapidly and, to-day, administrative costs have become a major expense in the operation of industrial firms. By 1948, for example, of every hundred production workers in British industrial firms, twenty were administrative employees; in 1907 the number was only eight.

Information collected by Seymour Melman shows that, in Great Britain at least, there has been no correlation between increases in administrative over. heads and the growth of productivity. (Manchester Guardian "Survey of Industry, Trade and Finance", 1954). In the United States, on the other hand, output per worker man-hour rose by 232 per cent from 1899 to 1947 while the administrative overhead ratio increased by over 40 per cent. In Great Britain the output per worker man-hour increased by 73 per cent from 1907 to 1948 while the ratio of administrative overheads grew by 133 per cent. It has been assumed that the growth in the cost of managing necessarily yields some economy in production; there is no evidence of any relationship of this kind.

Various reasons have been put forward to explain the growth of administrative costs in view of increasing mechanization and systematization. Melman suggests that increasing costs are due to the develop- 